\title{
3D Liquid Marble Microbioreactors Support In Vitro Maturation of Prepubertal Ovine Oocytes and Affect Expression of Oocyte-Specific Factors
}

\author{
Daniela Bebbere ${ }^{1, *(D)}$, Stefano Mario Nieddu ${ }^{1}$, Federica Ariu ${ }^{1}$, Davide Piras ${ }^{2}{ }^{\mathbb{D}}$ and Sergio Ledda ${ }^{1}$ \\ 1 Department of Veterinary Medicine, University of Sassari, 07100 Sassari, Italy; nieddino@hotmail.it (S.M.N.); \\ federica@uniss.it (F.A.); giodi@uniss.it (S.L.) \\ 2 Cell Dynamics S.r.l., Via Viola Cielia 62/d, 40026 Imola, Italy; davide.piras@celldynamics.it \\ * Correspondence: dbebbere@uniss.it
}

Citation: Bebbere, D.; Nieddu, S.M.; Ariu, F.; Piras, D.; Ledda, S. 3D Liquid Marble Microbioreactors Support In Vitro Maturation of Prepubertal Ovine Oocytes and Affect Expression of Oocyte-Specific Factors. Biology 2021, 10, 1101. https://doi.org/10.3390/ biology10111101

Academic Editor: Marc Yeste

Received: 28 September 2021

Accepted: 24 October 2021

Published: 25 October 2021

Publisher's Note: MDPI stays neutral with regard to jurisdictional claims in published maps and institutional affiliations.

Copyright: (c) 2021 by the authors. Licensee MDPI, Basel, Switzerland. This article is an open access article distributed under the terms and conditions of the Creative Commons Attribution (CC BY) license (https:// creativecommons.org/licenses/by/ $4.0 /)$.
Simple Summary: Oocyte in vitro maturation has broad potential for generating embryos for research and for application of assisted reproductive technologies, such as in vitro embryo production. In human, the possibility to efficiently mature oocytes in vitro would solve the reproductive problems of patients with special diseases. Nevertheless, the developmental ability of in vitro matured oocytes is currently lower than those matured in vivo. Here, we used young sheep oocytes as model of low-quality gametes to show that a novel liquid marble 3D culture system is suitable to mature in vitro oocytes with reduced potential, improving the rates of in vitro embryo production. The present findings are useful for the optimization of in vitro maturation systems, and to improve the developmental potential of in vitro matured oocytes. Further applications should be considered also in other species, including human, to mature oocytes with intrinsic low quality.

Abstract: In vitro oocyte maturation (IVM) is a well-established technique. Despite the high IVM rates obtained in most mammalian species, the developmental competence of IVM oocytes is suboptimal. The aim of this work was to evaluate the potential beneficial effects of a liquid marble microbioreactor (LM) as a 3D culture system to mature in vitro prepubertal ovine oocytes, as models of oocytes with intrinsic low competence. Cumulus-oocyte complexes of prepubertal sheep ovaries were in vitro matured in a LM system with hydrophobic fumed-silica-nanoparticles (LM group) or in standard conditions (4W control group). We evaluated: (a) maturation and (b) developmental rates following in vitro fertilization (IVF) and embryo culture; (c) expression of a panel of genes. LM and $4 \mathrm{~W}$ groups showed similar IVM and IVF rates, while in vitro development to blastocyst stage approached significance ( $4 \mathrm{~W}: 14.1 \%$ vs. LM: $28.3 \%$; $p=0.066$ ). The expression of GDF9, of enzymes involved in DNA methylation reprogramming and of the subcortical maternal complex was affected by the IVM system, while no difference was observed in terms of cell-stress-response. LM microbioreactors provide a suitable microenvironment to induce prepubertal sheep oocyte IVM and should be considered to enhance the developmental competence of oocytes with reduced potential also in other species, including humans.

Keywords: low developmental competence; gene expression; 3D in vitro culture

\section{Introduction}

Oocyte in vitro maturation (IVM) is an assisted reproductive technology designed to obtain mature oocytes following culture of immature cumulus-oocyte complexes (COCs) collected from antral follicles. It is a well-established technique largely applied to in vitro embryo production in the livestock field. In human, IVM implementation has been more challenging, and outcomes remain highly variable [1]; in the past decade, substantial improvements led to a more frequent application in clinical practice, which is expected to further increase in the future [2]. 
Despite the high IVM rates obtained in most mammalian species (ranging 60-90\%; [3], the developmental competence of in vitro matured oocytes is still suboptimal, as indicated by the relative low development to blastocyst stage and the poor viability to term after embryo transfer into recipients.

Two main factors lead to successful oocyte IVM: the system of IVM and the intrinsic quality of the oocyte. Several strategies were developed in different species to improve the IVM system, including formulation of specific maturation media [4], addition of growth factors and molecules [5,6], co-culture with different somatic cells [7] and modulating the length of in vitro culture [8,9]. Nevertheless, when oocytes with intrinsic reduced quality are matured in vitro, they have low chance to reach the MII stage and further developmental stages. Specific strategies to improve the developmental potential are therefore needed to support the maturation of such low competence gametes.

In recent years, studies on three-dimensional (3D) cell cultures have seen a wave of interest that led to the creation of accurate physiological and pathological models [10]. Specific 3D systems were also developed to support oocyte IVM in different species: alginate microbeads [11], agarose matrix [12] or glass scaffolds [13]. In 2016, we developed a microbioreactor using liquid marbles (LM) consisting of a polytetrafluoroethylene (PTFE) particle bed, as a novel system to support ovine oocyte IVM in small volumes [5]. LM microbioreactors were seen to provide a microenvironment capable of supporting oocyte IVM conducive to blastocyst development.

The aim of the present work is to evaluate potential beneficial effects of a liquid marble microbioreactor (LM) as a 3D culture system to mature in vitro oocytes with low developmental competence. For such purposes, oocytes of prepubertal sheep donors were selected as an appropriate model of reduced developmental potential due to their ability to undergo normal embryo development and produce viable offspring, albeit with lower rates [14]. To investigate the mechanisms potentially affected by the IVM system, we analyzed the expression a panel of genes involved in crucial aspects of oocyte biology.

\section{Materials and Methods}

All chemicals in this study were purchased from Sigma-Aldrich S.r.l. (Milan, Italy) unless stated otherwise.

\subsection{Ethics Approval}

The oocytes used for in vitro experiments in the present study were harvested from ovaries collected at a local slaughterhouse in Sardinia, Italy, which does not require ethics approval.

\subsection{Source of Oocytes and In Vitro Maturation}

Ovaries of adult (4-6 years old) and prepubertal (30-40 days old) Sarda sheep were collected from a local slaughterhouse in PBS solution (Dulbecco's phosphate buffered saline) containing penicillin $\left(100 \mu \mathrm{g} \mathrm{mL}^{-1}\right)$ and streptomycin $\left(100 \mu \mathrm{g} \mathrm{mL} \mathrm{m}^{-1}\right)$ at $37{ }^{\circ} \mathrm{C}$. Cumulus-oocytes complexes (COCs) were recovered by slashing in sterile Petri dishes containing dissection medium (20 mM Hepes-buffered TCM 199 supplemented with 0.1\% $(w / v)$ polyvinyl alcohol (PVA) and antibiotics). COCs with a uniform cytoplasm and several layers of unexpanded cumulus cells [15] were selected and randomly divided between two different IVM systems as outlined below.

\subsubsection{Control Group (4W)}

Groups of 30 35 COCs were matured in $600 \mu \mathrm{L}$ of TCM 199 supplemented with 10\% $(v / v)$ estrus sheep serum (OSS), $0.1 \mathrm{IU} \mathrm{mL}^{-1} \mathrm{FSH}$ and $0.1 \mathrm{IU} \mathrm{mL}^{-1} \mathrm{LH}$ (Pergonal, Serono, Italy), $8 \mathrm{mg} / \mathrm{mL}$ of pyruvate and $100 \mathrm{mM}$ cysteamine (IVM medium). COCs were cultured in four-well Petri dishes (Nunclon; Nalge Nunc International, Roskilde, Denmark) covered with $300 \mu \mathrm{L}$ preequilibrated mineral oil for $24 \mathrm{~h}$ under $5 \% \mathrm{CO}_{2}$ in air at $38.5^{\circ} \mathrm{C}$. 


\subsubsection{Liquid Marble Group (LM)}

The LM microbioreactor was created inside a Petri dish by preparing a hydrophobic fumed silica nanoparticle (Cab-O-Sil/Cabot) bed with particle size of $1 \mu \mathrm{m}$; a spatula was used to gently make a curved gully at the center of the powder bed (Figure 1). A micropipette was used to dispense the required volume $(30 \mu \mathrm{L})$ of IVM medium, containing a predetermined number of COCs (10 COCs for each drop) on the Cab-O-Sil/Cabot bed. The Petri dish was then gently shaken in a circular motion to ensure that the powder particles completely covered the surface of the liquid drop. The LM drops were transferred to new 35-mm Petri dishes and incubated for $24 \mathrm{~h}$ at $38.5^{\circ} \mathrm{C}$ in $5 \% \mathrm{CO}_{2}$ in air. To increase humidity and avoid dehydration, the Petri dishes were placed in a larger Petri dish containing sterile water and all Petri dishes were capped. All experiments were performed in three replicates.
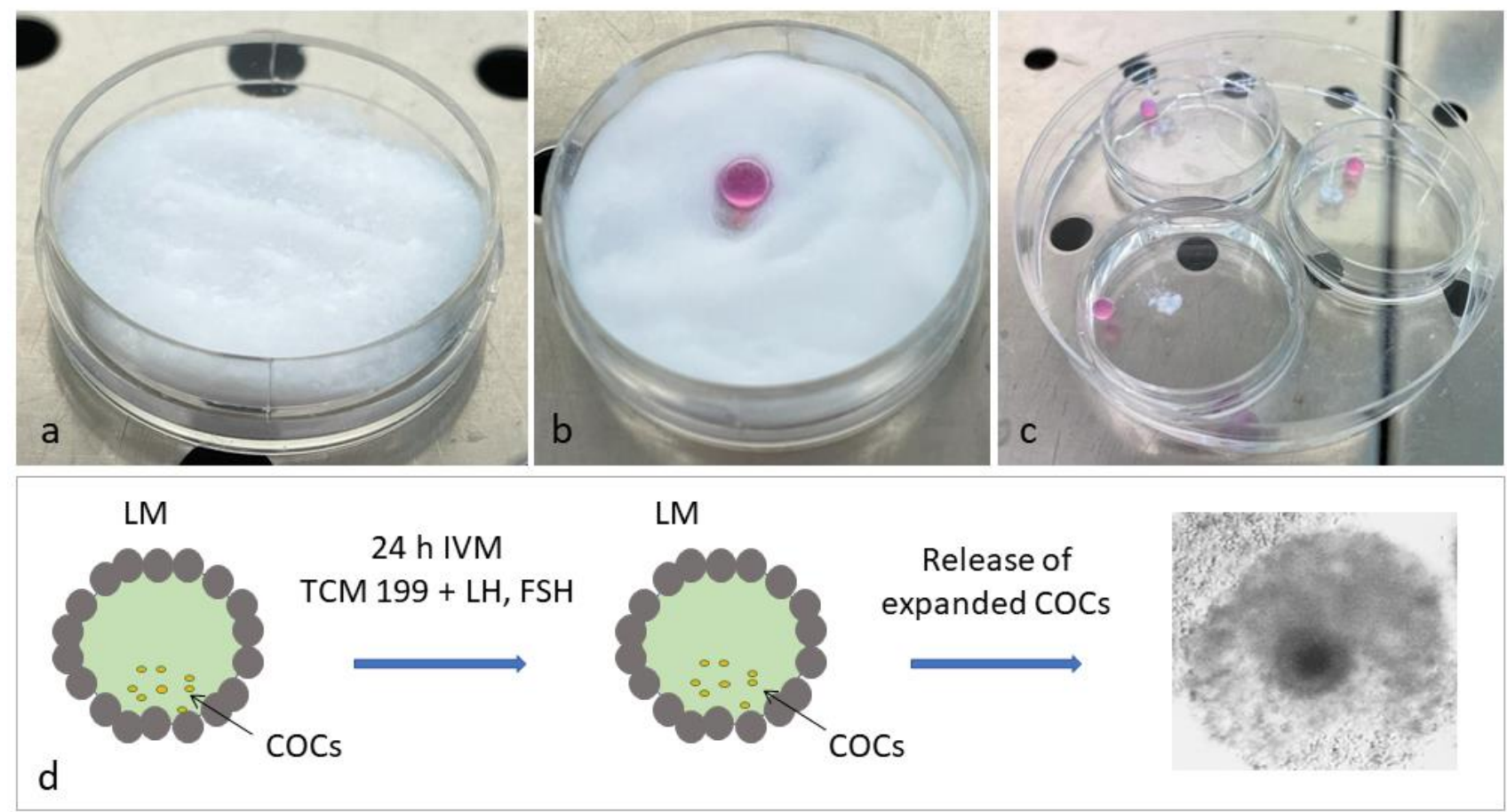

Figure 1. Preparation of liquid marbles (LM) containing COCs. (a) A hydrophobic Cab-O-Sil/Cabot powder bed is prepared in a 35-mm Petri dish. (b) Thirty $\mu \mathrm{L}$ of IVM medium, containing 10 COCs, are dispensed over the hydrophobic Cab-O-Sil/Cabot powder bed. The IVM drop is gently rolled over the powder to be fully coated with the Cab-O-Sil/Cabot particles. (c) The resulting LM drop is placed in a new 35-mm Petri dish positioned inside a larger Petri dish containing sterile water to prevent evaporation. (d) Schematic representation of IVM in Cab-O-Sil/Cabot powder LM.

\subsection{In Vitro Fertilization}

After $24 \mathrm{~h}$, in vitro matured prepubertal oocytes from the $4 \mathrm{~W}$ and LM systems were subjected to in vitro fertilization (IVF). COCs from the LM drops were released by the addition of IVM culture volume $(200 \mu \mathrm{L})$ over the LM drops. IVF was performed as previously described by Bebbere et al. [15], in synthetic oviductal fluid (SOF [16]) with $2 \%$ OSS, $1 \mu \mathrm{g} \mathrm{mL}{ }^{-1}$ heparin, $1 \mu \mathrm{g} \mathrm{mL} \mathrm{m}^{-1}$ hypotaurine for $22 \mathrm{~h}$ at $38.5^{\circ} \mathrm{C}$ and under a $5 \% \mathrm{CO}_{2}$, $5 \% \mathrm{O}_{2}$, and $90 \% \mathrm{~N}_{2}$ atmosphere in four-well Petri dishes with frozen/thawed spermatozoa selected by swim-up technique $\left(1 \times 10^{6}\right.$ spermatozoa $\left.\mathrm{mL}^{-1}\right)$.

\subsection{In Vitro Embryo Development}

IVF presumptive zygotes were cultured for 8 days in SOF with essential and nonessential amino acids at oviductal concentration [17], 0.4\% bovine serum albumin (BSA) under mineral oil, in four-well Petri dishes in maximum humidified atmosphere with 5\% 
$\mathrm{CO}_{2}, 5 \% \mathrm{O}_{2}$ and $90 \% \mathrm{~N}_{2}$ at $38.5^{\circ} \mathrm{C}$. Cleavage rates were recorded $40-48 \mathrm{~h}$ after the beginning of in vitro fertilization. Blastocyst development was recorded on day 8 (day $0=$ day of IVF).

\subsection{Gene Expression Analysis}

Gene expression analysis by real-time PCR was performed and is described according to MIQE guidelines [18] and in line with recent recommendations [19].

\subsection{Sample Collection for Gene Expression Analysis}

The RNA samples were isolated from pools of denuded oocytes derived from adult and prepubertal donors at the germinal vesicle (GV) stage and after IVM with the two systems (LM and $4 \mathrm{~W}$ ). Between 4 and 6 pools of 10 oocytes were analyzed per experimental group (Table 1). Oocytes were denuded via gentle pipetting to completely remove somatic cells and added to $30 \mu \mathrm{L}$ RLT buffer (RNeasy Micro Kit, Qiagen, Hilden, Germany), snapfrozen in liquid nitrogen, and stored at $-80^{\circ} \mathrm{C}$ until RNA isolation.

Table 1. Number of pools of ten oocytes used for gene expression analysis.

\begin{tabular}{cccc}
\hline & GV & LM-MII & 4W-MII \\
\hline Adult & 4 & 5 & 5 \\
\hline Prepubertal & 5 & 6 & 5 \\
\hline
\end{tabular}

\subsection{RNA Isolation and Reverse Transcription}

Total RNA was isolated from the groups of oocytes with the RNeasy Micro Kit (Qiagen, Hilden, Germany) following manufacturer's instructions. Five picograms of luciferase mRNA (Promega, The Netherlands) were added to each group prior to RNA isolation to account for RNA loss during the isolation process. During the procedure, RNA was treated with DNase I to exclude any potential genomic DNA contamination. Isolated RNA was eluted in $12 \mu \mathrm{L}$ RNase-free water and immediately used for reverse transcription polymerase chain reaction (RT-PCR). Reverse transcription was performed in a final volume of $20 \mu \mathrm{L}$, consisting of $75 \mathrm{mM} \mathrm{KCl}, 50 \mathrm{mM}$ Tris- $\mathrm{HCl}$ (pH 8.3), $5 \mathrm{mM}$ DTT, $3 \mathrm{mM} \mathrm{MgCl}_{2}$, $1 \mathrm{mM}$ dNTPs, $2.5 \mu \mathrm{M}$ random hexamer primers, $20 \mathrm{U}$ RNase OUT and $100 \mathrm{U}$ SuperScript III RT (all purchased at Invitrogen Corporation, Carlsbad, CA, USA). The reaction tubes were incubated at $25^{\circ} \mathrm{C}$ for $10 \mathrm{~min}$, at $42{ }^{\circ} \mathrm{C}$ for $1 \mathrm{~h}$ and at $70{ }^{\circ} \mathrm{C}$ for $15 \mathrm{~min}$ to inactivate the reaction. One tube without RNA and one with RNA, but without reverse transcriptase, were analyzed as negative controls. To quantify the mRNA recovery rate, $5 \mathrm{pg}$ of luciferase mRNA (not subjected to RNA isolation) were subjected to cDNA synthesis as well.

\subsection{Real-Time Polymerase Chain Reaction}

Primers were designed with Primer3 software, 0.4 .0 version (http:/ / frodo.wi.mit. edu/primer3/ accessed on 2 February 2021). The selected amplified regions were all intron-spanning as a further precaution to prevent amplification of trace genomic DNA, in the unlikely event of incomplete DNA digestion by DNase I (Table 2). Relative transcript quantification was performed by real-time polymerase chain reaction (RT-PCR) in a RotorGene Q MDx 5plex HRM (Qiagen). The PCR was performed in a $15 \mu \mathrm{L}$ reaction volume containing 7.5 $\mu \mathrm{L} 2 \times$ Quantinova SYBR Green PCR Kit (Qiagen, Germany), $200 \mathrm{nM}$ of each primer and cDNA equivalent to 0.25 oocytes. The PCR protocol consisted in two incubation steps $\left(50^{\circ} \mathrm{C}\right.$ for $5 \mathrm{~min}$ and $95^{\circ} \mathrm{C}$ for $2 \mathrm{~min}$ ), followed by 40 cycles of amplification $\left(95^{\circ} \mathrm{C}\right.$ for $15 \mathrm{~s}$ and gene-specific annealing temperature (see Table 2) for $30 \mathrm{~s}$ ), a melting curve program $\left(65-95^{\circ} \mathrm{C}\right.$, starting fluorescence acquisition at $65^{\circ} \mathrm{C}$ and measuring at 10 -s intervals until the temperature reached $95^{\circ} \mathrm{C}$ ), and a cooling step to $4{ }^{\circ} \mathrm{C}$. Fluorescence data were acquired during the annealing steps. To minimize handling variation, all samples were analyzed in the same run using a PCR master mix containing all reaction components apart from the sample. PCR products were analyzed by generating a melting curve to check specificity and identity of the amplification product. 
Table 2. Primers used for real-time PCR experiments. Ta: annealing temperature. Bps: base pairs.

\begin{tabular}{|c|c|c|c|c|c|}
\hline Symbol & Gene Name & Accession Number & Primer Sequence & Ta & bps \\
\hline$B A X$ & $\begin{array}{l}\text { BCL2 associated } \\
\mathrm{X} \text { protein }\end{array}$ & XM_004015363 & $\begin{array}{c}5^{\prime} \text { ctccccgagaggtctttttc } 3^{\prime} \\
5^{\prime} \text { tcgaaggaagtccaatgtcc } 3^{\prime}\end{array}$ & $58^{\circ} \mathrm{C}$ & 176 \\
\hline BMP15 & Bone morphogenetic protein 15 & NM_001114767 & $\begin{array}{l}5^{\prime} \text { gggttctacgactccgcttc } 3^{\prime} \\
5^{\prime} \text { ggttactttcaggcccatcat } 3^{\prime}\end{array}$ & $59^{\circ} \mathrm{C}$ & 173 \\
\hline DNMT1 & DNA methylation transferase 1 & NM_001009473 & $\begin{array}{l}5^{\prime} \text { cagctctcgtacatccacag } 3^{\prime} \\
5^{\prime} \text { aatctcgcgtagtcttggtc } 3^{\prime}\end{array}$ & $60^{\circ} \mathrm{C}$ & 158 \\
\hline DNMT3A & DNA methylation transferase 3A & XM_015094252 & $\begin{array}{l}5^{\prime} \text { gtgatgattgatgccaaaga } 3^{\prime} \\
5^{\prime} \text { ggtcctcactttgctgaact } 3^{\prime}\end{array}$ & $60^{\circ} \mathrm{C}$ & 165 \\
\hline DNMT3B & DNA methylation transferase 3B & XM_012189044 & $\begin{array}{l}5^{\prime} \text { attgcaacagggtacttggt } 3^{\prime} \\
5^{\prime} \text { atattgatgttgccctcgt } 3^{\prime}\end{array}$ & $60^{\circ} \mathrm{C}$ & 122 \\
\hline GDF9 & Growth differentiation factor 9 & NM_001142888 & $\begin{array}{c}5^{\prime} \text { cagacgccacctctacaaca } 3^{\prime} \\
5^{\prime} \text { caggaaagggaaaagaaatgg } 3^{\prime}\end{array}$ & $58^{\circ} \mathrm{C}$ & 198 \\
\hline HSP90b & Heat shock protein $90 \mathrm{~b}$ & XM_004018854 & $\begin{array}{l}5^{\prime} \text { tggagatcaaccctgacca } 3^{\prime} \\
5^{\prime} \text { gggatcctcaagcgagaag } 3^{\prime}\end{array}$ & $58^{\circ} \mathrm{C}$ & 143 \\
\hline KHDC3L & $\mathrm{KH}$ domain containing 3 like & XM_027973471 & $\begin{array}{l}5^{\prime} \text { cagaccetgcttcacgttca } 3^{\prime} \\
5^{\prime} \text { cttctcagagcttcgcgec } 3^{\prime}\end{array}$ & $60{ }^{\circ} \mathrm{C}$ & 150 \\
\hline LUC & Luciferase reporter vector $\mathrm{pXP} 2 * \mathrm{SA} * \mathrm{PS}$ & AF093685 & $\begin{array}{c}5^{\prime} \text { gctgggcgttaatcagagag } 3^{\prime} \\
5^{\prime} \text { gtgttcgtcttcgtcccagt } 3^{\prime}\end{array}$ & $58^{\circ} \mathrm{C}$ & 151 \\
\hline NLRP2 & NLR family pyrin domain containing 2 & XM_027977986 & $\begin{array}{c}5^{\prime} \text { gcatgtgttgctcattctgg } 3^{\prime} \\
5^{\prime} \text { agcactgtggaaacttgcag } 3^{\prime}\end{array}$ & $60^{\circ} \mathrm{C}$ & 120 \\
\hline NLRP5 & NLR family pyrin domain containing 5 & XM_027978862 & $\begin{array}{c}5^{\prime} \text { cagcctccaggagttctttg } 3^{\prime} \\
5^{\prime} \text { gacagcctaggagggtttcc } 3^{\prime}\end{array}$ & $59^{\circ} \mathrm{C}$ & 212 \\
\hline OOEP1 & Oocyte expressed protein isoform 1 & KF218578 & $\begin{array}{l}5^{\prime} \text { atccgctggtgttcttcctg } 3^{\prime} \\
5^{\prime} \text { gaacacggtgacttcgacc } 3^{\prime}\end{array}$ & $60^{\circ} \mathrm{C}$ & 149 \\
\hline PADI6 & Peptidyl arginine deiminase, type VI & XM_012153966 & $\begin{array}{l}5^{\prime} \text { acggetgtactccacctcac } 3^{\prime} \\
5^{\prime} \text { cccagacccaggttctctta } 3^{\prime}\end{array}$ & $60{ }^{\circ} \mathrm{C}$ & 109 \\
\hline SOD1 & Superoxide dismutase 1 & NM_001145185 & $\begin{array}{c}5^{\prime} \text { caactcccgccagcagat } 3^{\prime} \\
5^{\prime} \text { ccgggaatggacagtcaca } 3^{\prime}\end{array}$ & $58^{\circ} \mathrm{C}$ & 130 \\
\hline TET3 & Ten-eleven translocation 3 & XM_015094461 & $\begin{array}{l}5^{\prime} \text { tggagcatgtacttcaatgg } 3^{\prime} \\
5^{\prime} \text { ggtcacctggttctgatagg } 3^{\prime}\end{array}$ & $60{ }^{\circ} \mathrm{C}$ & 173 \\
\hline TLE6 & TLE family member 6 & XM_004009373 & $\begin{array}{l}5^{\prime} \text { gctgcaggtctccatcatct } 3^{\prime} \\
5^{\prime} \text { ggatcagctcaagcagcatt } 3^{\prime}\end{array}$ & $60^{\circ} \mathrm{C}$ & 134 \\
\hline YAP1 & Yes associated protein 1 & XM_015100723 & $\begin{array}{l}5^{\prime} \text { ttcctttgagatccetgacg } 3^{\prime} \\
5^{\prime} \text { gtcctgccaggttgttgtct } 3^{\prime}\end{array}$ & $60^{\circ} \mathrm{C}$ & 115 \\
\hline ZBED3 & $\begin{array}{l}\text { Zinc finger BED-type } \\
\text { containing } 3\end{array}$ & XM_027971476 & $\begin{array}{l}5^{\prime} \text { cccagggtagagtgtgcatt } 3^{\prime} \\
5^{\prime} \text { ggcaagggctactcatcaaa } 3^{\prime}\end{array}$ & $60^{\circ} \mathrm{C}$ & 97 \\
\hline
\end{tabular}

The efficiency of PCR reaction for each primer pair was previously assessed by building a standard curve with serial dilutions of a known amount of template, covering at least 3 orders of magnitude, so that the calibration curve's linear interval included the interval above and below the abundance of the targets. Only primers achieving an efficiency between 90 and $110 \%(3.6>$ slope $>3.1)$ and a coefficient of correlation $\left(r^{2}\right)>0.99$ were used for the analysis. The size of the amplification products was confirmed by electrophoresis on a $2 \%$ agarose gel in TBE $0.5 \mathrm{X}$ stained with SYBR Safe (Invitrogen) and visualized by exposure to blue light. The PCR products were sequenced (Model 3130 xl Genetic Analyzer; Applied Biosystems, Foster City, CA, USA) after purification with MinElute PCR purification kit (Qiagen, Hilden, Germany), and sequence identity was confirmed with BLAST (http:/ / www.ncbi.nlm.nih.gov/BLAST/ accessed on 10 April 2021). The relative quantification of all transcripts was performed after normalization against the number of oocytes and luciferase mRNA levels [20-22]. 


\subsection{Statistical Analysis}

Data were analyzed with GraphPad Prism version 8.0.0 for Windows (GraphPad Software, San Diego, CA, USA). In vitro maturation, fertilization and embryonic development rates were analyzed by chi-squared test at each time point.

After testing for normality using the Kolmogorov-Smirnov test, gene expression data were analyzed with the general linear model analysis of variance (ANOVA), followed by Tukey's post hoc comparison when significant differences among groups as a whole were observed.

Differences were considered significant when $p<0.05$.

\section{Results}

\subsection{In Vitro Maturation and Development}

After $24 \mathrm{~h}$ culture, the percentage of prepubertal COCs that reached MII did not differ between LM and $4 \mathrm{~W}$ groups ( $88 \%$ vs. $92.1 \%, p=0.374$ ), and no statistical difference was observed in the fertilization rate either (LM 69.7\% vs. $4 \mathrm{~W} 78.1 \%, p=0.248$ ). Conversely, in vitro development to blastocyst stage showed a better performance after IVM in the LM system (LM: $28.26 \%$ vs. $4 \mathrm{~W}: 14.06 \%$ ) with a $p$ value near the significance threshold $(p=0.066$; Table 3$)$.

Table 3. In vitro maturation, fertilization and development to blastocyst stage of prepubertal sheep oocytes cultured in liquid marble (LM) microbioreactor and control $(4 \mathrm{~W})$ systems. ${ }^{*} p=0.066$, chi-squared test.

\begin{tabular}{ccccc}
\hline & GV Oocytes & Matured Oocytes & Cleaved Embryos & Blastocysts \\
\hline $4 \mathrm{~W}$ & 89 & $82(92.13 \%)$ & $64(78.13 \%)$ & $9(14.06 \%)^{*}$ \\
\hline $\mathrm{LM}$ & 75 & $66(88 \%)$ & $46(69.7 \%)$ & $13(28.26 \%)^{*}$ \\
\hline
\end{tabular}

\subsection{Gene Expression Analysis}

To investigate the dynamics of a panel of transcripts during oocyte maturation in the two systems (LM and 4W), their abundance was observed before and after maturation. In addition, the patterns of gene expression during IVM of prepubertal oocytes were compared with the patterns observed during maturation of adult oocytes, to identify potential features associated with the developmental potential.

We selected genes involved in several crucial aspects of oocyte biology to gain an overall indication of oocyte reaction to the different environment (LM or 4W IVM system). We included: (i) components of the subcortical maternal complex, a recently discovered oocyte- and embryo-specific structure that affects several pathways ruling oocyte to embryo transition [23,24]; (ii) oocyte-secreted factors that play key roles in the oocyte developmental competence [25]; (iii) genes involved in cell stress response to address a potential response of the oocyte to a possibly adverse environment [26]; (iv) enzymes involved in DNA methylation reprogramming, which is fundamental for a proper epigenetic setup of the embryo and occurs immediately after fertilization, relying on the molecules stored in the gamete [27,28].

Specifically, the panel of analyzed genes comprised seven components of the subcortical maternal complex (KHDC3, NLRP2, NLRP5, OOEP, PADI6, TLE6 and ZBED3), three genes involved in cell stress response (BAX, HSP90b and SOD1), genes encoding three oocyte-secreted factors (BMP15, GDF9 and YAP1) and four enzymes involved in DNA methylation reprogramming in the early embryo (DNMT1, DNMT3A, DNMT3B and TET3). The presence of all analyzed transcripts was confirmed in all experimental groups.

\subsection{Expression of the SCMC Components}

In the prepubertal oocytes, a reduction in abundance of all transcripts was observed during maturation; such reduction is more prominent in the LM group $(p<0.05)$ compared to the $4 \mathrm{~W}$ control $(p>0.05$, except for ZBED3 ( $p<0.05$ in both groups); Figure 2). 
Prep KHDC3

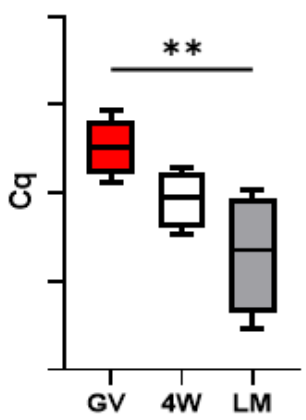

Prep PADI6

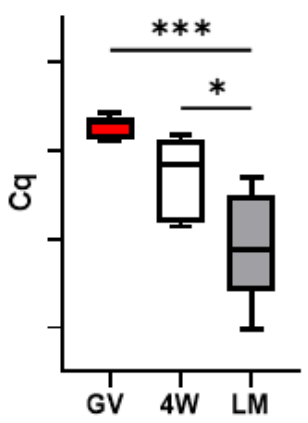

Prep NLRP2

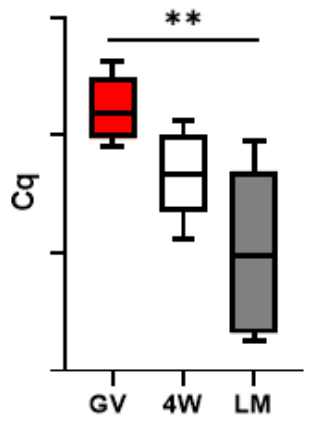

Prep TLE6

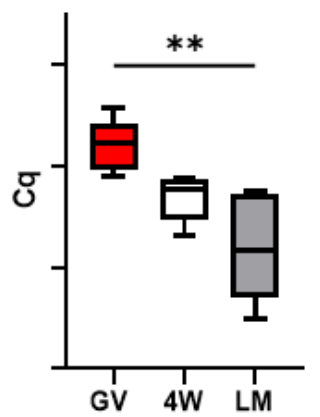

Prep NLRP5
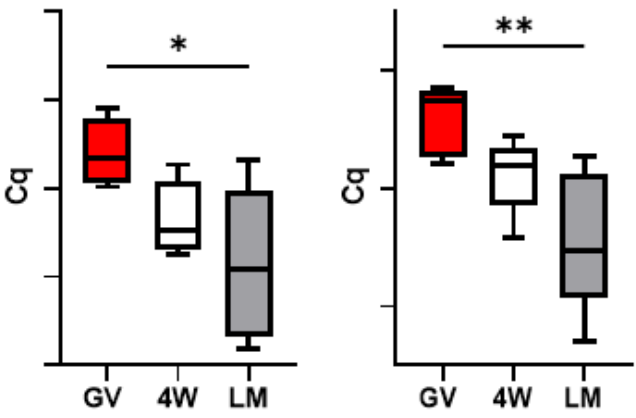

Figure 2. Expression of the subcortical maternal complex (SCMC) components in pools of prepubertal GV and MII oocytes matured in 4-well plates (4W) or in liquid marbles (LM). Target gene expression was normalized against the luciferase exogenous control. Relative abundance is expressed as $\Delta \mathrm{Cq}(Y$ axis). Each box represents the mean expression of 4-6 replicate pools of 10 oocytes each (mean \pm SE). Significant differences were assessed by ANOVA general linear model test; ${ }^{*} p<0.05,{ }^{* *} p<0.01$, *** $p<0.001$, **** $p<0.0001$.

Conversely, expression dynamics during maturation of adult gametes showed a similar trend in the two maturation systems for six genes (KHDC3, NLRP2, NLRP5, OOEP, PADI6 and TLE6), while ZBED3 decreases significantly in the $4 \mathrm{~W}$ group, but not in the LM (Figure 3). More specifically, KHDC3 and NLRP2 mRNA abundance did not show any significant variation between $\mathrm{GV}, 4 \mathrm{~W}$ and LM groups, while NLRP5, OOEP, PADI6 and TLE6 significantly decreased during maturation in both systems $(p<0.05)$.

\subsection{Expression of Genes Involved in Cell Stress Response}

A significant reduction in HSP90b, SOD1 and BAX mRNAs abundance was observed during in vitro maturation of prepubertal and adult oocytes in both standard $(4 \mathrm{~W})$ and LM systems (Figures 4 and 5).

\subsection{Expression of Genes Encoding Oocyte-Secreted Factors (OSF)}

The oocyte secreted factor BMP15 showed a significant reduction during maturation of prepubertal oocytes in the LM system, but not in the $4 \mathrm{~W}$ (Figure 6). Conversely, GDF9 transcript level decreased significantly in both $4 \mathrm{~W}$ and LM systems but also showed a significant difference between the two MII groups $(p<0.05)$, with a more prominent reduction in the oocytes matured in LM (Figure 6). YAP1 mRNA levels showed a significant drop over maturation in both IVM systems $(p<0.001)$. 
Ad $K H D C 3$

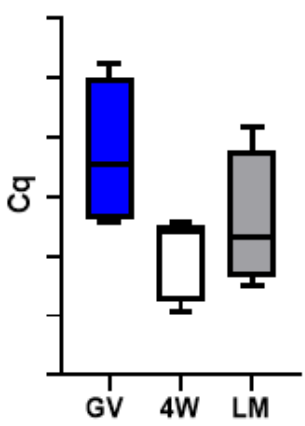

Ad NLRP2

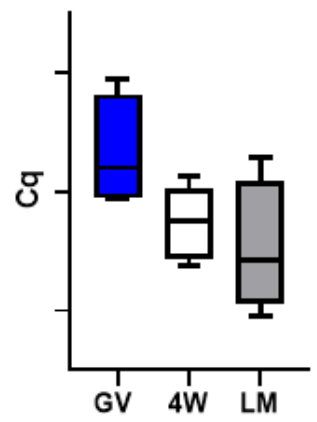

Ad TLE6

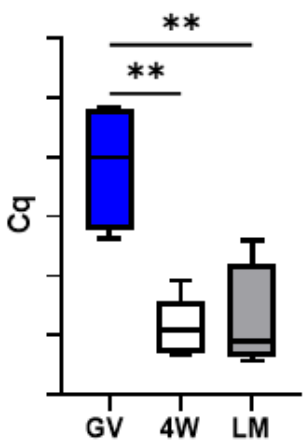

Ad NLRP5
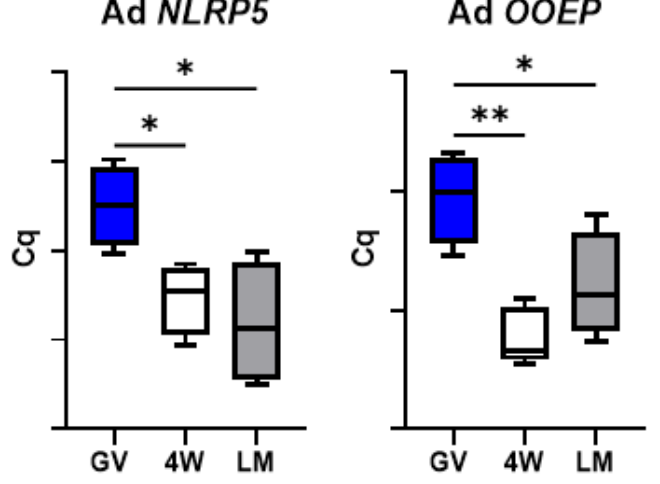

Figure 3. Expression of the subcortical maternal complex (SCMC) components in pools of adult GV and MII oocytes matured in 4-well plates (4W) or in liquid marbles (LM). Target gene expression was normalized against the luciferase exogenous control. Relative abundance is expressed as $\Delta \mathrm{Cq}$ ( $Y$-axis). Each box represents the mean expression of 5 replicate pools of 10 oocytes each (mean $\pm \mathrm{SE}$ ). Significant differences were assessed by ANOVA general linear model test; ${ }^{*} p<0.05,{ }^{* *} p<0.01$.
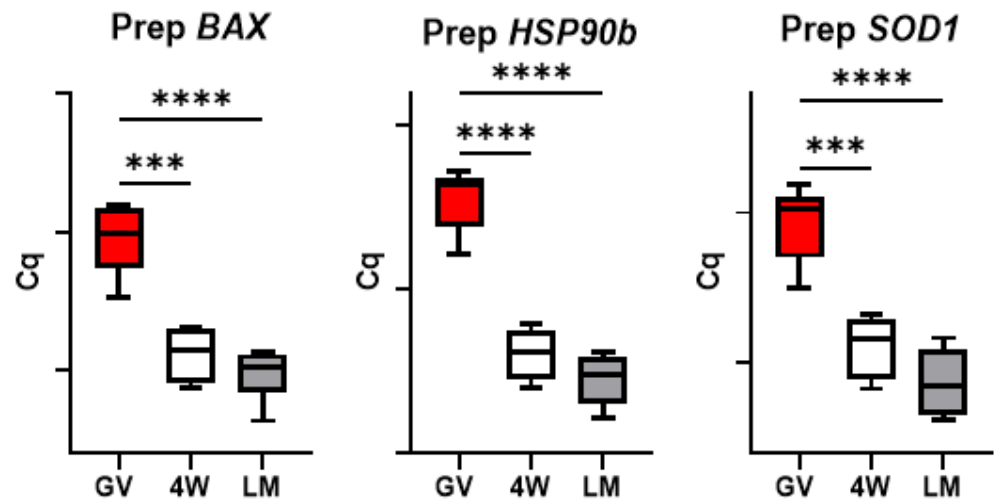

Figure 4. Expression of genes involved in cell stress response in pools of prepubertal GV and MII oocytes matured in 4-well plates (4W) or in liquid marbles (LM). Target gene expression was normalized against the luciferase exogenous control. Relative abundance is expressed as $\Delta \mathrm{Cq}$ ( $Y$-axis). Each box represents the mean expression of 5 replicate pools of 10 oocytes each (mean $\pm \mathrm{SE}$ ). Significant differences were assessed by ANOVA general linear model test; ${ }^{* * *} p<0.001,{ }^{* * * *} p<0.0001$. 

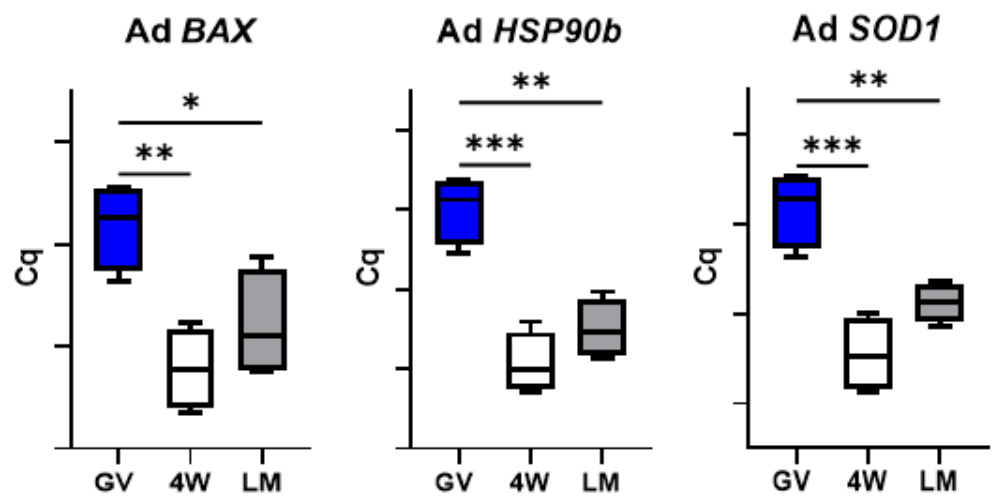

Figure 5. Expression of genes involved in cell stress response in pools of adult GV and MII oocytes matured in 4-well plates (4W) or in liquid marbles (LM). Target gene expression was normalized against the luciferase exogenous control. Relative abundance is expressed as $\Delta \mathrm{Cq}$ ( $Y$-axis). Each box represents the mean expression of 5 replicate pools of 10 oocytes each (mean $\pm \mathrm{SE}$ ). Significant differences were assessed by ANOVA general linear model test; ${ }^{*} p<0.05,{ }^{* *} p<0.01,{ }^{* * *} p<0.001$.

Prep BMP15

Prep GDF9

Prep YAP1
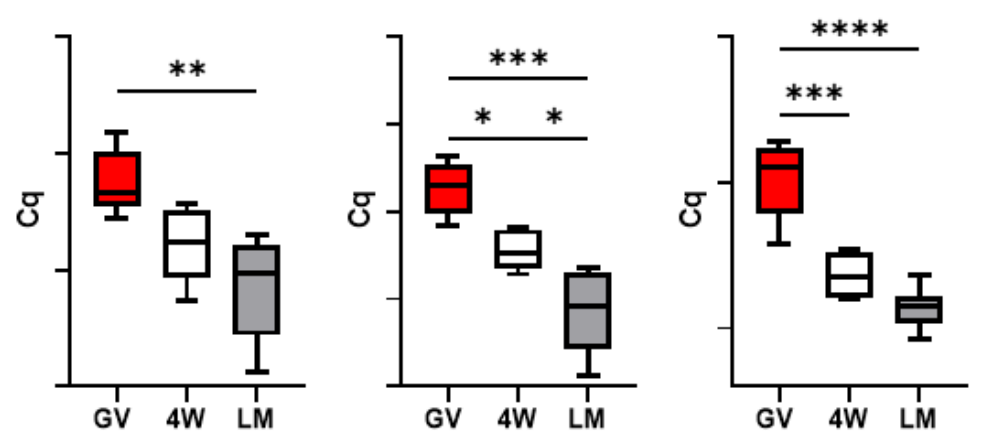

Figure 6. Expression of oocyte-secreted factors in pools of prepubertal GV and MII oocytes matured in 4-well plates (4W) or in liquid marbles (LM). Target gene expression was normalized against the luciferase exogenous control. Relative abundance is expressed as $\Delta \mathrm{Cq}$ ( $Y$-axis). Each box represents the mean expression of 5 replicate pools of 10 oocytes each (mean \pm SE). Significant differences were assessed by ANOVA general linear model test; ${ }^{*} p<0.05,{ }^{* *} p<0.01,{ }^{* * *} p<0.001,{ }^{* * * *} p<0.0001$.

Conversely, GDF9 expression in adult oocytes dropped over maturation but did not show any difference between the two systems (Figure 7). Similarly, YAP1 mRNA level was reduced after IVM in both system and showed no difference between $4 \mathrm{~W}$ and LM $(p<0.01)$. Finally, $B M P 15$ transcript level decreased significantly during maturation in the standard system $(4 \mathrm{~W} ; p<0.05)$, but not in the LM.

\subsection{Expression of Enzymes Involved in DNA Methylation Reprogramming}

Differently from the other groups of analyzed genes, the expression of the enzymes involved in DNA methylation reprogramming in prepubertal oocytes was always affected by the type of IVM system. DNMT1, DNMT3A and DNMT3B expression decreased after maturation in both systems, while TET3 abundance did not vary after maturation in the standard 4W, but significantly dropped in the LM $(p<0.001$; Figure 8). Importantly, TET3, DNMT1, DNMT3A and DNMT3B transcript level differed between $4 \mathrm{~W}$ and LM groups, with a more prominent reduction in the oocytes matured in LM (Figure 8). 

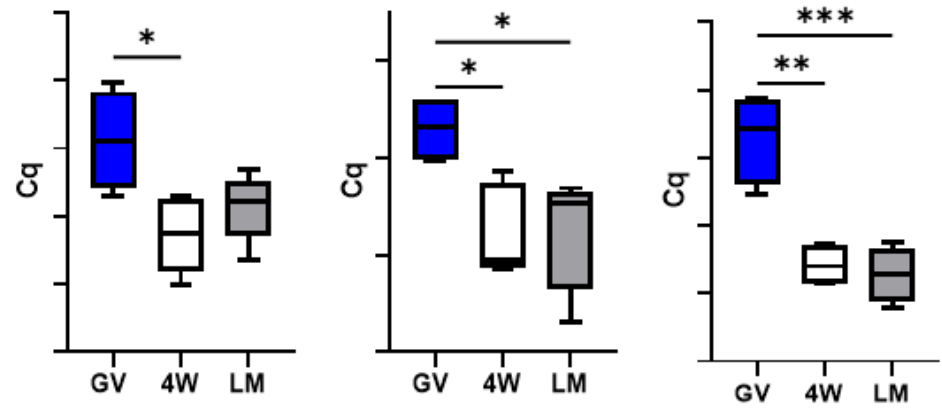

Figure 7. Expression of oocyte-secreted factors in pools of adult GV and MII oocytes matured in 4-well plates $(4 \mathrm{~W})$ or in liquid marbles (LM). Target gene expression was normalized against the luciferase exogenous control. Relative abundance is expressed as $\Delta \mathrm{Cq}(Y$-axis). Each box represents the mean expression of 5 replicate pools of 10 oocytes each (mean $\pm \mathrm{SE}$ ). Significant differences were assessed by ANOVA general linear model test; ${ }^{*} p<0.05,{ }^{* *} p<0.01,{ }^{* * *} p<0.001$.

Prep DNMT1

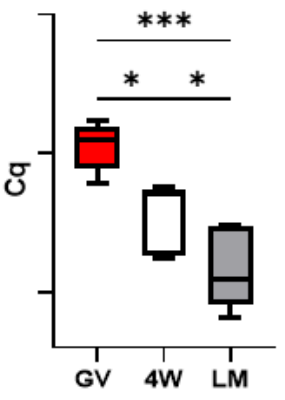

Prep DNMT3A

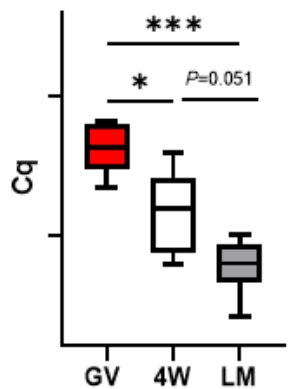

Prep DNMT3B

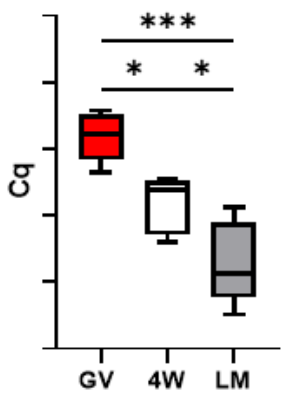

Prep TET3

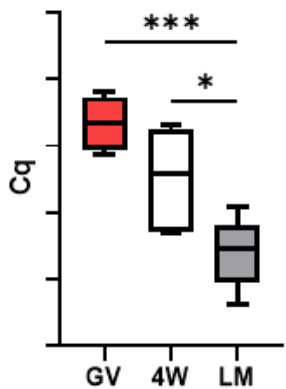

Figure 8. Expression of genes involved in DNA methylation reprogramming in pools of prepubertal GV and MII oocytes matured in 4-well plates (4W) or in liquid marbles (LM). Target gene expression was normalized against the luciferase exogenous control. Relative abundance is expressed as $\Delta \mathrm{Cq}$ ( $Y$-axis). Each box represents the mean expression of 5 replicate pools of 10 oocytes each (mean $\pm \mathrm{SE})$. Significant differences were assessed by ANOVA general linear model test; ${ }^{*} p<0.05,{ }^{* * *} p<0.001$.

On the contrary, expression of the four genes in adult oocytes did not differ after IVM in the two systems (Figure 9).

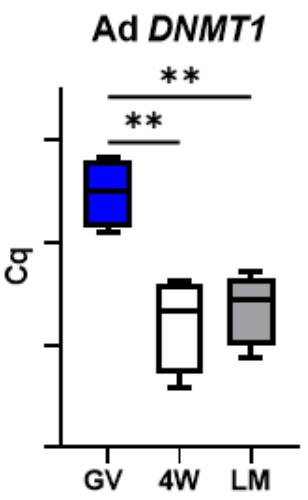

Ad DNMT3A

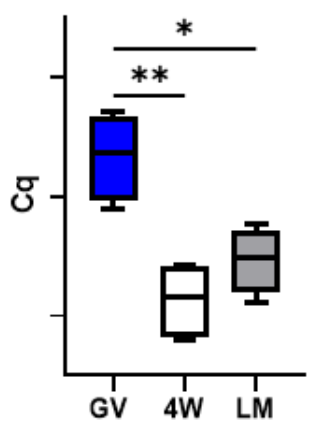

Ad DNMT3B

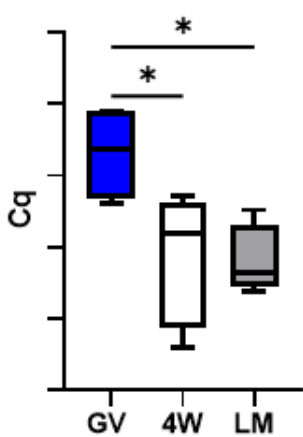

Ad TET3

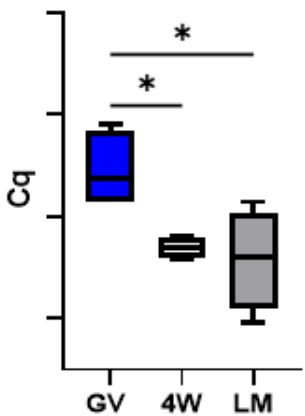

Figure 9. Expression of genes involved in DNA methylation reprogramming in pools of adult GV and MII oocytes matured in 4-well plates (4W) or in liquid marbles (LM). Target gene expression was normalized against the luciferase exogenous control. Relative abundance is expressed as $\Delta \mathrm{Cq}$ ( $Y$-axis). Each box represents the mean expression of 5 replicate pools of 10 oocytes each (mean $\pm \mathrm{SE}$ ). Significant differences were assessed by ANOVA general linear model test; ${ }^{*} p<0.05,{ }^{* *} p<0.01$. 


\section{Discussion}

The present work showed that LM microbioreactors provide a suitable microenvironment to induce prepubertal oocyte IVM and may be used to enhance their developmental competence, as indicated by the improved blastocyst rates and by the expression patterns of specific genes.

LM is a scaffold-free 3D microbioreactor that provides the most suitable conditions for cell aggregation. Allowing the maintenance of the physiological architecture of female gametes, it better simulates the follicular environment during meiotic maturation. In accordance, we previously showed that LM properly supports IVM of ovine oocytes of adult donors, with similar developmental rates to standard IVM systems [5]. In the present work, we show that oocytes with reduced developmental competence further benefit from a 3D culture system that minimizes the negative effects of the traditional 2D IVC (i.e., cumulus cell flattening and adhesion to the 2D support). COCs suspension in the maturation medium preserves physiological cell organization, with potential positive effects on oocyte and cumulus cell molecular, metabolic and developmental competence [29].

The blastocyst rate observed for prepubertal oocytes cultured in the LM microbioreactors is higher compared to the rate observed for the standard IVM system, with a relative $p$ value near the significance threshold $(p=0.066)$. Possibly, the blastocyst rate did not reach statistical significance owing to the small number of IVP embryos (Table 3).

To gain further insights on the effects of IVM in LM, we considered the gene expression status of the oocyte before maturation and after IVM in the LM and in the standard (4W) systems. The oocyte transcriptome is assembled during the growth phase of oogenesis and is completed with the arrest of transcription in full-grown prophase I GV oocytes [30]. Oocyte maturation is associated with a major wave of maternal RNA degradation [22]. This absolute reduction in mRNA content, due to translation or active degradation, results in relative changes to transcript dosage in the MII transcriptome [22,31], which are fundamental for the establishment of oocyte competence to sustain fertilization and early embryo development [32,33].

Presuming a potential effect of the in vitro system on transcript use (translation or degradation), we evaluated the expression of a panel of genes involved in important processes of oocyte maturation and early embryo development. We selected seven components of the subcortical maternal complex (SCMC), three genes involved in cell stress response, three genes encoding oocyte-secreted factors and four encoding enzymes involved in DNA methylation reprogramming in the early embryo. This last group of genes was the most affected by the IVM system. The genes encoding three DNA methyl transferases (DNMT1, $D N M T 3 A$ and DNMT3B) and the enzymes TET3, which is responsible for DNA hydroxymethylation leading to demethylation [27], all showed a significantly lower transcript abundance in the oocytes matured in LM (Figure 8). This suggests a more efficient use of the mRNAs in the 3D system. DNMT and TET enzymes regulate the genome-wide DNA methylation reprogramming that occurs in early embryos, immediately after fertilization $[27,28]$; such epigenetic remodeling is essential for the new developmental program of the nascent embryo and is therefore crucial to oocyte developmental competence.

Oocyte-secreted factors (OSFs) are further key players in the acquisition of oocyte developmental competence, being involved in a bidirectional cross-talk via gap junctions between oocyte and cumulus cells [25]. Among them, GDF9 and BMP15 are crucial regulators of the growth and differentiation of granulosa cells, which in turn supply the oocyte with the support necessary for future healthy embryo/fetal development [25]. The different expression of GDF9 we observed after maturation in the two systems suggests that LMs better preserve the physiological communication between somatic cells and the oocyte compared to the standard $4 \mathrm{~W}$ system (Figure 6). Three dimensional in vitro culture probably allows better maintenance of COCs architecture and communication through gap-junctions and ensures proper functional activities.

Even if not different in terms of transcript abundance between LM and $4 \mathrm{~W}$, some genes showed diverse patterns of mRNA regulation over transcription, with a more prominent 
decrease over maturation in the LM system $(p<0.05)$ and a less evident reduction in the standard IVM conditions ( $4 \mathrm{~W} ; p<0.05)$. This was observed in six of the seven components of the SCMC (Figure 2) and in one OSF (BMP15; Figure 6) and indicates by some means an effect of the IVM system on these transcripts turnover. The SCMC is a crucial structure for oocyte biology, being involved in several key processes leading the transition from oocyte to embryo, including meiotic spindle formation and positioning, regulation of translation, organelle redistribution, and epigenetic reprogramming [23,24]. The complex is also involved in human genetic infertility, therefore any variation in its expression most probably affects the oocyte developmental potential.

Finally, two further aspects deserve attention. The similar transcript abundance of genes involved in cell stress response in the two IVM systems (Figure 4) indicates the absence of a specific stress due to the LM system itself. In addition, the significant differences observed between the two systems (LM and $4 \mathrm{~W}$ ) in the prepubertal oocytes were not found in the adult counterpart. This was observed for the genes involved in DNA methylation reprogramming (Figure 9), for GDF9 (Figure 7) and for the SCMC components (except ZBED3; Figure 3) and is in accordance with the in vitro developmental rates (Table 3). In our previous work, we indeed observed similar developmental rates for adult oocytes matured in LM or in standard conditions [5], while in the present work we report a better performance of prepubertal oocytes in the LMs.

\section{Conclusions}

In conclusion, LM microbioreactors provide a suitable microenvironment to induce oocyte IVM and may be used to improve the developmental competence of prepubertal ovine oocytes. Such system should be considered to improve the maturation and developmental rates of gametes with intrinsic low developmental competence also in other species. In human clinics, improving the success rate by optimizing the IVM culture system has a major significance. Many human oocytes exhibit maturation arrest in vitro because of intrinsic low developmental competence due to several factors (age, genetics, pathologies, exposure to environmental or behavioral conditions). Therefore, identifying novel IVM systems specifically beneficial to low competence oocytes is significant to the improvement of assisted reproductive technologies.

Author Contributions: Data curation, D.B.; funding acquisition, S.L.; investigation, D.B., S.M.N., F.A. and D.P.; methodology, D.B. and S.L.; resources, S.L.; writing-original draft, D.B.; writing-review and editing, D.B. All authors have read and agreed to the published version of the manuscript.

Funding: The present work was funded by CUP J86C18000800005/Fondazione Banco di Sardegna.

Institutional Review Board Statement: Ethical review and approval were waived for this study due to fact that the oocytes used for the experiments were harvested from ovaries collected at a local slaughterhouse in Sardinia, Italy, which does not require ethics approval.

Informed Consent Statement: Not applicable.

Data Availability Statement: The data produced during the current study are available from the corresponding author on reasonable request.

Conflicts of Interest: The authors declare no conflict of interest. The funders had no role in the design of the study; in the analyses or interpretation of data; in the writing of the manuscript or in the decision to publish the results.

\section{References}

1. Sánchez, F.; Lolicato, F.; Romero, S.; De Vos, M.; Van Ranst, H.; Verheyen, G.; Anckaert, E.; Smitz, J.E.J. An improved IVM method for cumulus-oocyte complexes from small follicles in polycystic ovary syndrome patients enhances oocyte competence and embryo yield. Hum. Reprod. 2017, 32, 2056-2068. [CrossRef]

2. De Vos, M.; Grynberg, M.; Ho, T.M.; Yuan, Y.; Albertini, D.F.; Gilchrist, R.B. Perspectives on the development and future of oocyte IVM in clinical practice. J. Assist. Reprod. Genet. 2021, 38, 1265-1280. [CrossRef] [PubMed]

3. Gilchrist, R.B.; Thompson, J.G. Oocyte maturation: Emerging concepts and technologies to improve developmental potential in vitro. Theriogenology 2007, 67, 6-15. [CrossRef] 
4. Farsi, M.M.; Kamali, N.; Pourghasem, M. Embryological aspects of oocyte in vitro maturation. Int. J. Mol. Cell. Med. 2013, 2, 99-109. [PubMed]

5. Ledda, S.; Idda, A.; Kelly, J.; Ariu, F.; Bogliolo, L.; Bebbere, D. A novel technique for in vitro maturation of sheep oocytes in a liquid marble microbioreactor. J. Assist. Reprod. Genet. 2016, 33, 513-518. [CrossRef]

6. Uhm, S.J.; Gupta, M.K.; Yang, J.H.; Chung, H.J.; Min, T.S.; Lee, H.T. Epidermal growth factor can be used in lieu of folliclestimulating hormone for nuclear maturation of porcine oocytes in vitro. Theriogenology 2010, 73, 1024-1036. [CrossRef] [PubMed]

7. Lin, Y.H.; Hwang, J.L.; Seow, K.M.; Huang, L.W.; Chen, H.J.; Tzeng, C.R. Effects of growth factors and granulosa cell co-culture on in-vitro maturation of oocytes. Reprod. BioMed. Online 2009, 19, 165-170. [CrossRef]

8. You, J.; Lee, E.; Bonilla, L.; Francis, J.; Koh, J.; Block, J.; Chen, S.; Hansen, P.J. Treatment with the proteasome inhibitor MG132 during the end of oocyte maturation improves oocyte competence for development after fertilization in cattle. PLoS ONE 2012, 7, e48613. [CrossRef]

9. Donnay, I.; Faerge, I.; Grøndahl, C.; Verhaeghe, B.; Sayoud, H.; Ponderato, N.; Galli, C.; Lazzari, G. Effect of prematuration, meiosis activating sterol and enriched maturation medium on the nuclear maturation and competence to development of calf oocytes. Theriogenology 2004, 62, 1093-1107. [CrossRef] [PubMed]

10. Antoni, D.; Burckel, H.; Josset, E.; Noel, G. Three-dimensional cell culture: A breakthrough in vivo. Int. J. Mol. Sci. 2015, 16, 5517-5527. [CrossRef]

11. Mastrorocco, A.; Cacopardo, L.; Martino, N.A.; Fanelli, D.; Camillo, F.; Ciani, E.; Roelen, B.A.J.; Ahluwalia, A.; Dell'Aquila, M.E. One-step automated bioprinting-based method for cumulus-oocyte complex microencapsulation for 3D in vitro maturation. PLoS ONE 2020, 15, e0238812. [CrossRef]

12. Park, J.E.; Kim, M.S.; Lee, E.; Lee, S.T. In vitro maturation using an agarose matrix with incorporated extracellular matrix proteins improves porcine oocyte developmental competence by enhancing cytoplasmic maturation. J. Tissue Eng. Regen. Med. 2021, 15, 807-817. [CrossRef]

13. Shen, P.; Xu, J.; Wang, P.; Zhao, X.; Huang, B.; Wu, F.; Wang, L.; Chen, W.; Feng, Y.; Guo, Z.; et al. A new three-dimensional glass scaffold increases the in vitro maturation efficiency of buffalo (Bubalus bubalis) oocyte via remodelling the extracellular matrix and cell connection of cumulus cells. Reprod. Domest. Anim. 2020, 55, 170-180. [CrossRef]

14. Ledda, S.; Bebbere, D.; Ariu, F.; Pescatori, M.; Pau, S.; Zedda, M.T.; Bogliolo, L. Unveiling mRNA changes during meiotic progression and pre-implantation development: Help from large animal models. Curr. Pharm. Des. 2012, 18, 256-263. [CrossRef] [PubMed]

15. Bebbere, D.; Bogliolo, L.; Ariu, F.; Fois, S.; Leoni, G.G.; Tore, S.; Succu, S.; Berlinguer, F.; Naitana, S.; Ledda, S. Expression pattern of zygote arrest 1 (ZAR1), maternal antigen that embryo requires (MATER), growth differentiation factor 9 (GDF9) and bone morphogenetic protein 15 (BMP15) genes in ovine oocytes and in vitro-produced preimplantation embryos. Reprod. Fertil. Dev. 2008, 20, 908-915. [CrossRef]

16. Tervit, H.R.; Whittingham, D.G.; Rowson, L.E. Successful culture in vitro of sheep and cattle ova. J. Reprod. Fertil. 1972, 30, 493-497. [CrossRef]

17. Walker, S.K.; Hill, J.L.; Kleemann, D.O.; Nancarrow, C.D. Development of ovine embryos in synthetic oviductal fluid containing amino acids at oviductal fluid concentrations. Biol. Reprod. 1996, 55, 703-708. [CrossRef] [PubMed]

18. Bustin, S.A.; Benes, V.; Garson, J.A.; Hellemans, J.; Huggett, J.; Kubista, M.; Mueller, R.; Nolan, T.; Pfaffl, M.W.; Shipley, G.L.; et al. The MIQE guidelines: Minimum information for publication of quantitative real-time PCR experiments. Clin. Chem. 2009, 55, 611-622. [CrossRef] [PubMed]

19. Taylor, S.C.; Nadeau, K.; Abbasi, M.; Lachance, C.; Nguyen, M.; Fenrich, J. The ultimate qPCR experiment: Producing publication quality, reproducible data the first time. Trends Biotechnol. 2019, 37, 761-774. [CrossRef]

20. Ohsugi, M.; Zheng, P.; Baibakov, B.; Li, L.; Dean, J. Maternally derived FILIAMATER complex localizes asymmetrically in cleavage-stage mouse embryos. Development 2008, 135, 259-269. [CrossRef]

21. Evsikov, A.V.; Marín de Evsikova, C. Gene expression during the oocyte-to embryo transition in mammals. Mol. Reprod. Dev. 2009, 76, 805-818. [CrossRef] [PubMed]

22. Su, Y.Q.; Sugiura, K.; Woo, Y.; Wigglesworth, K.; Kamdar, S.; Affourtit, J.; Eppig, J.J. Selective degradation of transcripts during meiotic maturation of mouse oocytes. Dev. Biol. 2007, 302, 104-117. [CrossRef] [PubMed]

23. Bebbere, D.; Masala, L.; Albertini, D.F.; Ledda, S. The subcortical maternal complex: Multiple functions for one biological structure? J. Assist. Reprod. Genet. 2016, 33, 1431-1438. [CrossRef] [PubMed]

24. Bebbere, D.; Albertini, D.F.; Coticchio, G.; Borini, A.; Ledda, S. The subcortical maternal complex: Emerging roles and novel perspectives. Mol. Hum. Reprod. 2021, 27, gaab043. [CrossRef]

25. Gilchrist, R.B.; Lane, M.; Thompson, J.G. Oocyte-secreted factors: Regulators of cumulus cell function and oocyte quality. Hum. Reprod. Update 2008, 14, 159-177. [CrossRef]

26. Haase, M.; Fitze, G. HSP90AB1: Helping the good and the bad. Gene 2016, 575 Pt 1, 171-186. [CrossRef]

27. Ito, S.; D'Alessio, A.C.; Taranova, O.V.; Hong, K.; Sowers, L.C.; Zhang, Y. Role of Tet proteins in 5mC to 5hmC conversion, ES-cell self-renewal and inner cell mass specification. Nature 2010, 466, 1129-1133. [CrossRef]

28. Okano, M.; Bell, D.W.; Haber, D.A.; Li, E.T DNA methyltransferases Dnmt3a and Dnmt3b are essential for de novo methylation and mammalian development. Cell 1999, 99, 247-257. [CrossRef] 
29. Morselli, M.G.; Luvoni, G.C.; Comizzoli, P. The nuclear and developmental competence of cumulus-oocyte complexes is enhanced by three-dimensional coculture with conspecific denuded oocytes during in vitro maturation in the domestic cat model. Reprod. Domest. Anim. 2017, 52 (Suppl. 2), 82-87. [CrossRef]

30. Eppig, J.J.; Schroeder, A.C. Capacity of mouse oocytes from preantral follicles to undergo embryogenesis and development to live young after growth, maturation, and fertilization in vitro. Biol. Reprod. 1989, 41, 268-276. [CrossRef]

31. Ma, J.; Flemr, M.; Strnad, H.; Svoboda, P.; Schultz, R.M. Maternally recruited DCP1A and DCP2 contribute to messenger RNA degradation during oocyte maturation and genome activation in mouse. Biol. Reprod. 2013, 88, 11. [CrossRef] [PubMed]

32. Ivanova, I.; Much, C.; Di Giacomo, M.; Azzi, C.; Morgan, M.; Moreira, P.N.; Monahan, J.; Carrieri, C.; Enright, A.J.; O’Carroll, D. The RNA m(6)A Reader YTHDF2 Is Essential for the Post-transcriptional Regulation of the Maternal Transcriptome and Oocyte Competence. Mol. Cell 2017, 67, 1059-1067.e4. [CrossRef] [PubMed]

33. Li, L.; Zheng, P.; Dean, J. Maternal control of early mouse development. Development 2010, 137, 859-870. [CrossRef] [PubMed] 